\title{
Türk Eğitim Sisteminde Teknolojinin Etkin Kullanımı İçin Yapılan Projeler: 1984-2013 Dönemi
}

\author{
Arif Cem Topuz ${ }^{1}$, Yüksel Göktaş² \\ ${ }^{1}$ Bilgisayar Teknolojileri Bölümü, Ardahan Üniversitesi, Ardahan, Türkiye \\ ${ }^{2}$ Bilgisayar ve Öğretim Teknolojileri Bölümü, Erzurum Atatürk Üniversitesi, Erzurum, Türkiye \\ arifcemtopuz@ardahan.edu.tr, yuksel.goktas@ hotmail.com \\ (Geliş/Received: 09.02.2015; Kabul/Accepted: 03.04.2015) \\ DOI: $10.17671 / \mathrm{btd} .43357$
}

\begin{abstract}
Özet- Bu araştırmanın amacı, Türk eğitim sisteminde teknolojinin daha etkin kullanımı için 1984-2013 yılları arasında yapılan projeleri analiz etmektir. Araştırma kapsamında ilgili dönemde yapılan 32 projenin bilgilerine ulaşılmıştır. Veriler, ilgili kurum ve kuruluşların web siteleri ve yayınladıkları resmi doküman ve raporlardan elde edilmiş̧ir. Araştırma bulguları, otuz yıllık süreçte Türk eğitim sisteminde teknolojinin daha etkin kullanımı için azımsanmayacak miktarda yatırım yapıldığını göstermektedir. Bu yatırımlara rağmen önceki yıllarda yapılan projelerin sonuçlarının yeterli düzeyde analiz edilmediği, projelere ait veri tabanları oluşturulmadığı, proje yürütenlerin dahi ilgili verileri saklamadığı ve bu durumların sonucu olarak ilgili alandaki ihtiyacı karşılamak amacıyla nasıl bir proje yapılması gerektiği analiz edilmeksizin sadece teknolojiyi satın almak ile eğitim sistemine entegre edilmiş olacağı düşüncesiyle yapılan projelerin olduğu gözlenmiştir. 32 proje bilgilerinin derlenerek literatüre kazandırıldığ bu çalışmada verilerin toplandığı web kaynaklarından bazılarına artık ulaşılamadığı düşünüldüğünde, bu çalışmanın gelecekte projeler hakkında bilgiye ulaşmak isteyen araştırmacılar için ne derece önemli bir kaynak olacağı çok net anlaşılabilmektedir.
\end{abstract}

\section{Projects for Effective Technology Use in Turkish Education System: Period of 1984-2013}

\begin{abstract}
This research aims to analyze the projects which have been implemented in 1984-2013 in order to use the technology in Turkish Education System, effectively. Data of 32 projects were examined diligently for this study. The data were obtained from relevant foundations and enterprises' web sites and from their official published documents and reports. Research results show that substantial amounts of investment were made to the effective usage of technology in Turkish Education System during three decades. It's revealed that despite these investments, the results of the projects, which were implemented in previous years were not analyzed properly. In addition, they the databases were not produced about the projects and were not kept the relevant data. With this regard, without consideration of the needs, it has been observed that analyses were integrated to the education system by only purchasing technology. In conclusion, recent study was reviewed of these 32 projects data and brought in the literature. Some of web resources that contain data are not available anymore. This data will be an important source for the researchers who seek the projects' data in the future.
\end{abstract}

Keywords - Ministry of Education's Projects, Technological Developments in Education, Education Policies 


\section{GİRIŞ (INTRODUCTION)}

Özellikle 1980'den sonra, bilișim teknolojilerinde (BT) görülen hızlı gelişmeler, günümüz toplumlarının tüm sistemlerini önemli ölçüde etkilemiştir. Bu gelişmelerden etkilenen sistemlerden birisi de hiç kuşkusuz eğitim sistemidir [1]. Bu durumun bir sonucu olarak "Ekonomik İşbirliği ve Kalkınma Teşkilatı'nın (OECD) yayınladı̆̆ bir rapora göre, ülkelerin çoğu; yüksek kalitede öğrenme ve öğretim hizmeti sağlamak, bireyleri modern toplumun gerekliliklerine göre donatmak ve onların sosyal ve ekonomik başarılarını artırmak için okullara önemli ölçüde BT yatırımı yapmaktadır” [2].
Patrikas ve Newton'a göre, BT'yi eğitim-öğretim süreçleriyle bütünleştirmek ve etkin kullanmak için yeterli düzeyde ekonomik kaynağın ayrılması ve bu ayrılan kaynağın etkili ve verimli bir şekilde kullanılması gerekmektedir [3]. $\mathrm{Bu}$ sürecin başarıya ulaşmasında en önemli anahtarlardan birisi doğru planlamadır. Son yıllarda eğitimde BT'nin daha etkin kullanımı için Türk eğitim sistemi hızlı bir gelișim ve değișim içerisindedir. Milli Eğitim Bakanlığı (MEB) sorumluluğunda ilerleyen süreçte bu amaçla birçok çalışma yapılmıştır. Yürütülen çalışmalar incelendiğinde MEB'in eğitimde daha etkin BT kullanımı faaliyetleri iki boyutta ele alınabilir. Bu boyutlar Tablo 1'de şu şekilde belirtilmiştir [4].

Tablo 1. MEB Bilgi Toplumu faaliyetleri

(Ministry of Education's Information Society activities)

\begin{tabular}{ll}
\hline \multicolumn{1}{c}{ Patandaşlara ve Kamu Kurumlarında Çalışanlara Yönelik } & \multicolumn{1}{c}{ Öğretmen ve Öğrencilere Yönelik Projeler } \\
\hline E- Sınav Uygulamaları & Okullarda Temel BT Eğitimi \\
BT Eğitimi Sertifikasyonu & BT ile Desteklenen Örgün Eğitim \\
Kamu İnternet Erişim Merkezleri (KİEM) & BT ile Desteklenen Yaygın Eğitim \\
Yetişkinlere Temel BT Kursları & Eğitim Portalı ve Bilgi Sistemi \\
Kamu Çalışanlarına Temel BT Kursları & Okullarda BT Altyapısı \\
Bilgisayar ve İnternet Kampanyası & Eğitim Yazılımları Geliştirme Kapasitesinde \\
& Öğretmen Eğitimi \\
\hline
\end{tabular}

Boyutlardan birincisi vatandaşlara ve kamu çalıșanlarına yönelik olup daha çok BT kullanımının yaygın eğitim yoluyla kazandırılması yönündeki çalışmalardır. İkinci boyut ise bu çalışmanın da kapsamını oluşturan Milli Eğitim Bakanlığı'na bağlı eğitim kurumlarında çalışan öğretmenlere ve bu eğitim kurumlarında öğrenim görmekte olan öğrencilere yönelik çalışmalardır. Bakanlık, okulların BT altyapısını kurmaya ve geliştirmeye yönelik çalışmalar düzenlemektedir. $\mathrm{Bu}$ kapsamda Dünya Bankası, Avrupa Yatırım Bankası, Intel, Microsoft gibi uluslararası kuruluş ve firmalarla iletişime geçip protokoller imzalamıştır. Bakanlık okullarda BT altyapısının kurulmasının yanı sıra; okullarda görevli personelin ve öğrencilerin BT kullanımının yaygınlaştırılmasına yönelik de projeler yürütmektedir [4]. Milli Eğitim Bakanlığg'nın okullarda BT altyapısının oluşturulması ve eğitimde BT kullanımının yaygınlaştırılmasına yönelik 1984-2013 yılları arasında yürüttüğü ya da desteklediği projeler için literatür taraması yapılmış, Milli Eğitim Bakanlığı Projeler Koordinasyon Merkezi Başkanlığı web sayfası [5] ve 'Verilerin Toplanması' bölümünde belirtilen diğer kaynaklardan yararlanılarak proje adlarının yer aldığ 1 Tablo 2 oluşturulmuştur.

Tablo 2. 1984-2013 yılları arasında yapılan MEB projeleri

(Ministry of Education projects which carried out between the years 1984-2013)

\begin{tabular}{|c|c|c|c|}
\hline No & $\begin{array}{c}\text { Okullarda BT Altyapısının Oluşturulmasına } \\
\text { Yönelik Projeler }\end{array}$ & No & $\begin{array}{c}\text { Okullarda BT Kullanımının Yaygınlaştırılmasına } \\
\text { Yönelik Projeler }\end{array}$ \\
\hline 1 & Endüstriyel Okullar Projesi & 15 & $\begin{array}{l}\text { World Links Projesi } \\
\text { Türk-Japon Teknik İs Birliği Kapsamında Anadolu }\end{array}$ \\
\hline 2 & Milli Eğitimi Geliştirme Projesi & 16 & $\begin{array}{l}\text { Teknik Liselerinde Endüstriyel Otomasyon } \\
\text { Teknolojileri Bölümü Kurulması Projesi }\end{array}$ \\
\hline 3 & Temel Eğitim Projesi I. Fazı & 17 & Eğitim Çerçevesi Projesi I. Fazı \\
\hline 4 & İLSİS Projesi & 18 & $\begin{array}{l}\text { Temel Eğitime Destek Programı (Temel Eğitim } \\
\text { Projesi I. Fazı) }\end{array}$ \\
\hline 5 & Temel Eğitim Projesi II. Fazı & 19 & Intel Gelecek İçin Eğitim \\
\hline 6 & MEB İnternete Erişim Projesi & 20 & Internet Radyo TV \\
\hline 7 & $\begin{array}{l}\text { Mesleki ve Teknik Eğitimin Modernizasyonu } \\
\text { Projesi }\end{array}$ & 21 & Microsoft Eğitimde İşbirliği \\
\hline 8 & Bilgisayarlı Eğitime Destek Kampanyası & 22 & Bilişim Teknolojileri Projesi \\
\hline 9 & $\begin{array}{l}\text { Ortaöğretimi Geliştirme Projesi } \\
\text { Endüstriyel Teknik Öğretim Okulları }\end{array}$ & 23 & Skoool.tr Portalı \\
\hline 10 & $\begin{array}{l}\text { Bünyesinde Video Konferans Sistemi (Akıllı } \\
\text { Sinıf) Kurulması Projesi }\end{array}$ & 24 & Eğitim Çerçevesi Projesi II. Fazı \\
\hline 11 & MEB Kapasitesinin Güçlendirilmesi Projesi & 25 & Uzaktan Eğitim Sistemi Uygulamalarının AB \\
\hline
\end{tabular}




\begin{tabular}{|c|c|c|c|}
\hline 12 & MEBBİS & 26 & $\begin{array}{l}\text { Ülkelerindeki Uygulama Yöntemleri Projesi } \\
\text { Mesleki Teknik Eğitimde Uygulanabilir Bilgi Sistemi } \\
\text { Projesi (METUBIS) }\end{array}$ \\
\hline 13 & $\begin{array}{l}\text { İTEC “Katılımcı Sınıf İçin Yenilikçi } \\
\text { Teknolojiler” Projesi }\end{array}$ & 27 & Think.com Portalı \\
\hline \multirow[t]{5}{*}{14} & $\begin{array}{l}\text { Fırsatları Artırma, Teknolojiyi İyileştirme } \\
\text { Hareketi (FATİH) Projesi }\end{array}$ & 28 & Intel Öğretmen Programı \\
\hline & & 29 & $\begin{array}{l}\text { Uzmanlaşmış Meslek Edindirme Merkezleri Projesi } \\
\text { (UMEM) }\end{array}$ \\
\hline & & 30 & Hayat Boyu Öğrenmenin Geliştirilmesi Projesi \\
\hline & & 31 & $\begin{array}{l}\text { Türkiye'de Mesleki ve Teknik Eğitimin Kalitesinin } \\
\text { Geliștirilmesi Projesi }\end{array}$ \\
\hline & & 32 & Hayat Boyu Öğrenmenin Geliştirilmesi Operasyonu 2 \\
\hline
\end{tabular}

Tablo 1 ve Tablo 2'den anlaşılacağı üzere teknolojinin eğitim sisteminde daha etkin kullanımını sağlamak amacıyla MEB tarafindan çeşitli projeler yapılmıştır. $\mathrm{Bu}$ amaçla 1984'ten başlayarak günümüze kadar yapılan tüm proje bilgilerinin derlenerek analiz edilmesi bu çalışmanın amacını oluşturmaktadır. Araştırma kapsamındaki süreçte, MEB için yapılan projeler analiz edilerek Türk eğitim sisteminde teknoloji kullanımı konusunda yapılan projelerin neler olduğu ortaya çıkarılmaya çalışılmıştır.

$\mathrm{Bu}$ çalışma bireysel araştırmacılar açısından eğitimde teknoloji kullanımı için yatırım yapılan projelerin neler olduğunu görme konusunda önemli bir kaynak niteliğindedir. Tamamlanan veya devam eden projelere ait bilgilere ulaşılabilecek temel bir kaynak olmaması ve mevcut web kaynaklarının bir süre sonra yayından kaldırılıyor olması göz önünde bulundurulduğunda, tek kaynaktan 32 projeye dair tüm bilgilere ulaşılabilen bu çalışma ile literatüre önemli bir katkı sağlanmaktadır. Eğitim sistemi için yapılan teknolojik yatırımların incelendiği az sayıdaki çalışmadan biri olan bu araştırmanın, Kalkınma ve Milli Eğitim Bakanlığı için politika üretirken katkı sağlayacağı düşünülmektedir. Bu amaçla aşağıdaki araştırma sorularına cevap aranmıştır.

Türk eğitim sisteminde teknolojinin daha etkin kullanımı için 1984-2013 yılları arasında yapılan;

1. Projelerin yıllara göre dağılımı nasıldır?

2. Projeleri destekleyen kurumlar hangileridir?

3. Projelerin bütçeleri ne kadardır?

4. Projelerin amaçları nelerdir?

5. Projeler sonucunda hangi faaliyetler yapılmıştır?

\section{YÖNTEM (METHOD)}

\subsection{Araştırma Deseni (Research Design)}

Çalışma nitel desende doküman analizi yöntemi kullanılarak yapılmıştır. Doküman analizinde temel amaç; "araştırılması hedeflenen olgu veya olgular hakkında bilgi içeren yazılı materyallerin analiz edilmesidir” [6].

\subsection{Verilerin Toplanması (Collection of Data)}

Çalışma kapsamında, Türkiye'de son otuz yılda (19842013) teknolojinin Türk eğitim sisteminde daha etkin kullanımı için Milli Eğitim Bakanlığı'na bağlı okullarda yapılan proje bilgilerine ulaşılması hedeflenmiştir. Milli Eğitim Bakanlığı'nın Çıraklık ve Yaygın Eğitim Genel Müdürlüğü [7], Eğitim Teknolojileri Genel Müdürlüğü [8], Mesleki ve Teknik Eğitim Genel Müdürlüğü [9], Projeler Koordinasyon Merkezi Başkanlığı [2], [10], Strateji Geliştirme Başkanlığı [11] ile Bilim, Sanayi ve Teknoloji Bakanlığı [12], Türkiye İstatistik Kurumu [13] ve Kalkınma Bakanlığı [14] (Devlet Planlama Teşkilatı) raporlarından, projeler hakkında bilgi veren akademik çalışmalar [15] ve web sitelerinden [16] veriler toplanmıştır. Yapılan tarama sonucunda 1984 ile 2013 yılları arasında toplam 32 proje yapıldığı tespit edilmiş (Tablo 2) ve bu projelerden elde edilen bilgiler çalışmanın verilerini oluşturmuştur. Projelerden araştırma soruları doğrultusunda Tablo 3 'te belirtilen veriler toplanmıştır.

Tablo 3. Projelerden toplanan veriler (Datas which were collected from the projects)

\begin{tabular}{|c|c|c|c|c|c|}
\hline $\begin{array}{l}\bar{\tau} \\
0 \\
0 \\
0 \\
0 \\
0\end{array}$ & 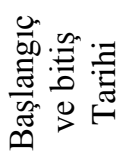 & 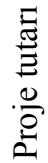 & 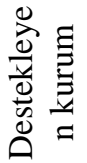 & 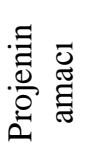 & 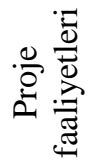 \\
\hline$\ldots$ & $\ldots$ & $\ldots$ & $\ldots$ & $\ldots$ & $\ldots$ \\
\hline
\end{tabular}

Veri toplama süresince 4982 sayılı bilgi edinme kanunu çerçevesinde projeleri destekleyen bazı kurum ve kuruluşlarla yazışmalar yapılmıştır. $\mathrm{Bu}$ kurum ve kuruluşlardan bazıları (Ulusal Ajans, TÜBİTAK, Ulaştırma, Denizcilik ve Haberleşme Bakanlığı, Kalkınma Bakanlığı, SODES, MEB), başvuruya herhangi bir yanıt vermemiş ya da bugüne kadar destekledikleri proje bilgilerini düzenli olarak tutmadıklarını ve bu sebeple bilgi gönderemeyeceklerini belirten yazılı yanıtlar göndermişlerdir.

\subsection{Verilerin Analizi (Data Analysis)}

Analiz sürecinin birinci aşamasında, Türk eğitim sisteminde teknolojinin daha etkin kullanımını sağlamak 
amacıyla yapılan projelere ait bilgiler toplanmıştır. İkinci aşamada, Tablo 3'te bulunan alanlara proje bilgileri girilmiştir. Ulaşılan dokümanlarda proje bütçeleri hakkında bilgi karmaşası olduğu tespit edilmiş ve bu durumlarda proje bütçeleri alanına Kalkınma Bakanlığı'nın yılsonu yatırım planlarında belirtilen ödeme miktarları yazılmıştır. Son olarak anlam kazanan veriler neticesinde, neden-sonuç ilişkileri kurulmuş, bulgulardan bir takım sonuçlar çıkarılmış ve elde edilen sonuçların önemine ilişkin açıklamalar yapılmıştır.

\subsection{Geçerlik ve Güvenirlik (Validity and Reliability)}

Genel anlamda geçerlik araştırma sonuçlarının doğruluğunu konu edinir. Nitel araştırmalarda geçerlik, üzerinde çalışılan olgu veya konudan elde edilen verilerin teyit edilmesine yardımc1 olacak "katılımc1 teyidi", "meslektaş teyidi" veya "uzman incelemesi" gibi bazı ek yöntemlerin kullanılması ile sağlanabilir [6]. Çalışmanın ve verilerin geçerliği; iki meslektaş ve bir uzman tarafından araştırma soruları, veriler ve bulguların gözden geçirilmesi ile kontrol edilmiştir.

Güvenirlik araştırma sonuçlarının tekrar edilebilirliği ile ilgilidir. LeCompte vd. iç güvenirlik için; başka araştırmacıların aynı veriyi kullanarak aynı sonuçlara ulaşıp ulaşamayacağı, dış güvenirlik için; araştırma sonuçlarının benzer ortamlarda aynı şekilde elde edilip edilemeyeceği şeklinde ifade etmiștir [6]. Çalıșmanın ve verilerin güvenirliği; araştırmaya birden fazla araştırmacının dâhil edilmesi, ulaşılan sonuçların teyit edilmesi ve verilerin betimsel bir yaklaşımla doğrudan sunulması ile sağlanmıştır.

\section{BULGULAR (FINDINGS)}

\subsection{Projelerin Yıllara Göre Dağılımı (Distribution of Projects by Year)}

Okullarda BT altyapısının oluşturulmasına yönelik yapılan projelerin yıllara göre dağılımı Tablo 4'te gösterilmiştir. Bu tablodan anlaşılacağı üzere; 1986-1989 ve 1998 yılları hariç son otuz yıllık sürede, eğitim sisteminde teknolojinin daha etkin kullanımı için okullarda BT altyapısının oluşturulmasına yönelik sürekli projelerin yapıldığı görülmektedir. Günümüzde ise 3 proje halen devam etmektedir.

Tablo 4'te ayrıca BT kullanımının yaygınlaştırılmasına yönelik yapılan projelerin yıllara göre dağılımı da gösterilmiştir. Bu tablodan anlaşılacağı üzere; okullarda BT kullanımının yaygınlaşmasına yönelik projeler 1997 yılı itibariyle başlamıştır. Projelerin 6 tanesi günümüzde halen faaliyetlerine devam etmektedir. 
Tablo 4. Projelerin yıllara göre dağılımı (Distribution of projects by year)

\begin{tabular}{|c|c|c|c|c|c|c|c|c|c|c|c|c|c|c|c|c|c|c|c|c|c|c|c|c|c|c|c|c|c|c|c|}
\hline & & $\mathrm{A}$ & tya & Dis & IIn & & $\begin{array}{ll}\mathrm{Ir} \\
\mathrm{er}\end{array}$ & ll & $\mathrm{a}$ & a $Y$ & Tö & & & & & $\mathrm{Ku}$ & llar & nımı & nın & Yas & ygin & llaşt & .riln & nası & Ina & Yön & elik & Pro & jele & & \\
\hline 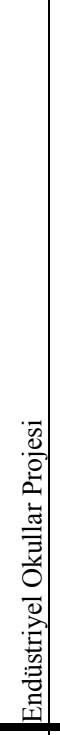 & 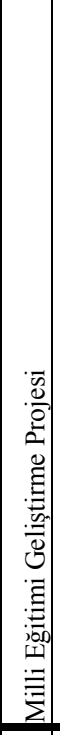 & 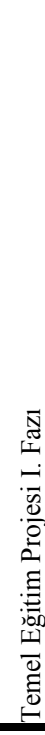 & & 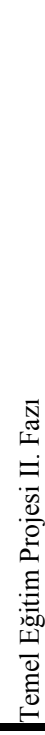 & 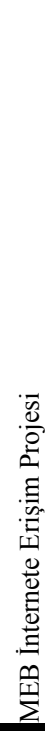 & 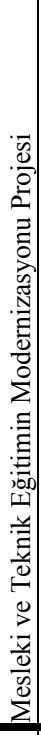 & 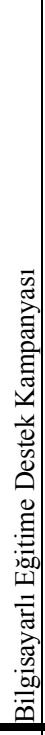 & 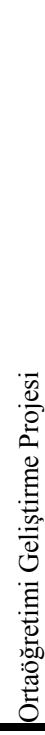 & 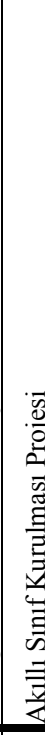 & 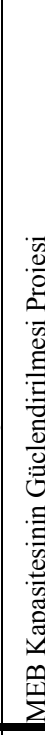 & 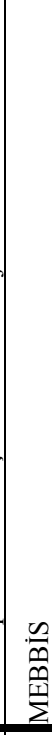 & 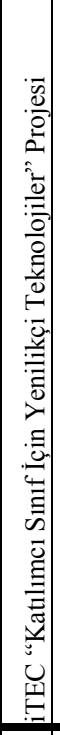 & 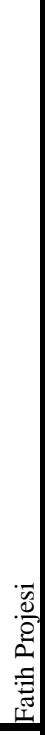 & 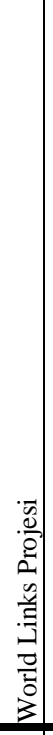 & 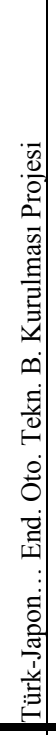 & 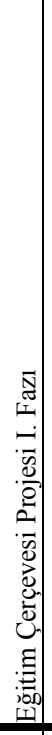 & 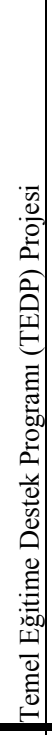 & 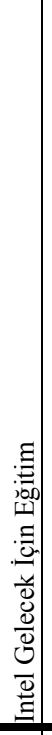 & 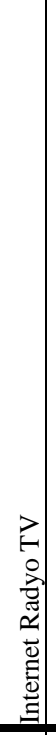 & 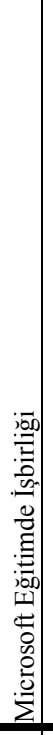 & 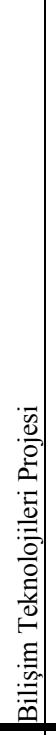 & 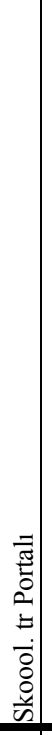 & 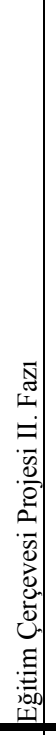 & 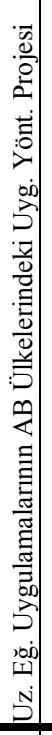 & 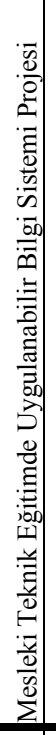 & 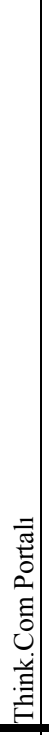 & 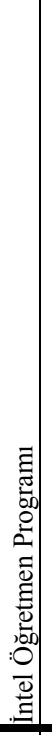 & 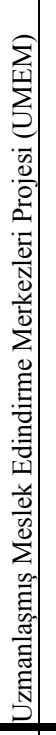 & 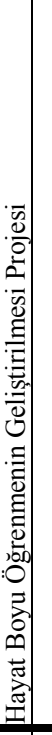 & 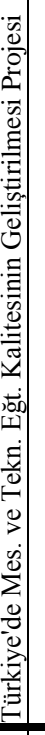 & 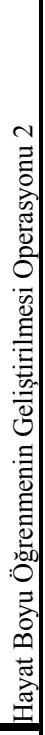 \\
\hline 1 & 2 & 3 & 4 & 5 & 6 & 7 & 8 & 9 & 10 & 11 & 12 & 13 & 14 & 15 & 16 & 17 & 18 & 19 & 20 & 21 & 22 & 23 & 24 & 25 & 26 & 27 & 28 & 29 & 30 & 1 & 32 \\
\hline & & & & & & & & & & & & & & & & & & & & & & & & & & & & & & & \\
\hline & & & & & & & & & & & & & & & & & & & & & & & & & & & & & & & \\
\hline & & & & & & & & & & & & & & & & & & & & & & & & & & & & & & & \\
\hline & & & & & & & & & & & & & & & & & & & & & & & & & & & & & & & \\
\hline & & & & & & & & & & & & & & & & & & & & & & & & & & & & & & & \\
\hline & & & & & & & & & & & & & & & & & & & & & & & & & & & & & & & \\
\hline & & & & & & & & & & & & & & & & & & & & & & & & & & & & & & & \\
\hline & & & & & & & & & & & & & & & & & & & & & & & & & & & & & & & \\
\hline & & & & & & & & & & & & & & & & & & & & & & & & & & & & & & & \\
\hline & & & & & & & & & & & & & & & & & & & & & & & & & & & & & & & \\
\hline & & & & & & & & & & & & & & & & & & & & & & & & & & & & & & & \\
\hline & & & & & & & & & & & & & & & & & & & & & & & & & & & & & & & \\
\hline & & & & & & & & & & & & & & & & & & & & & & & & & & & & & & & \\
\hline & & & & & & & & & & & & & & & & & & & & & & & & & & & & & & & \\
\hline & & & & & & & & & & & & & & & & & & & & & & & & & & & & & & & \\
\hline & & & & & & & & & & & & & & & & & & & & & & & & & & & & & & & \\
\hline & & & & & & & & & & & & & & & & & & & & & & & & & & & & & & & \\
\hline & & & & & & & & & & & & & & & & & & & & & & & & & & & & & & & \\
\hline & & & & & & & & & & & & & & & & & & & & & & & & & & & & & & & \\
\hline & & & & & & & & & & & & & & & & & & & & & & & & & & & & & & & \\
\hline & & & & & & & & & & & & & & & & & & & & & & & & & & & & & & & \\
\hline & & & & & & & & & & & & & & & & & & & & & & & & & & & & & & & \\
\hline & & & & & & & & & & & & & & & & & & & & & & & & & & & & & & & \\
\hline & & & & & & & & & & & & & & & & & & & & & & & & & & & & & & & \\
\hline & & & & & & & & & & & & & & & & & & & & & & & & & & & & & & & \\
\hline & & & & & & & & & & & & & & & & & & & & & & & & & & & & & & & \\
\hline & & & & & & & & & & & & & & & & & & & & & & & & & & & & & & & \\
\hline & & & & & & & & & & & & & & & & & & & & & & & & & & & & & & & \\
\hline & & & & & & & & & & & & & & & & & & & & & & & & & & & & & & & \\
\hline & & & & & & & & & & & & & & & & & & & & & & & & & & & & & & & \\
\hline
\end{tabular}




\subsection{Projeleri Destekleyen Kurumlar (Corporations that Supported the Projects)}

Eğitim sisteminde teknolojinin daha etkin kullanımı için yapılan projeler birçok kurum ve kuruluş tarafindan desteklenmiştir. Milli Eğitim Bakanlığ başka kurum ve kuruluşlarla işbirliği yapmıştır. $\mathrm{Bu}$ işbirlikleri çerçevesinde Dünya Bankası fonları, Avrupa Yatırım Bankası fonları, JICA (Japan International Cooperation Agency) fonları ve $\mathrm{AB}$ fonları ile projeleri finanse etmiştir. Projeler yoluyla sağlanan kaynakların bir bölümü hibe ama önemli bir bölümü kredidir. 1984-2013 yılları arasında teknolojinin eğitimde etkili şekilde kullanımı için yapılan proje bütçelerinin Milli Eğitim Bakanlığ 1 haricindeki kaynaklarını gösteren grafik Şekil 1'de verilmiştir.

Şekil 1. 1984-2013 yılları arasında yapılan projelerin finans kaynakları (Financial resources of the projects which done between the years 1984-2013)

\subsection{Projelerin Bütçeleri (Budget of the Projects)}

Okullarda BT altyapısının oluşturulmasına yönelik yapılan projelerin bütçeleri Tablo 5'te, Okullarda BT kullanımının yaygınlaştırılmasına yönelik yapılan projelerin bütçeleri Tablo 6'da verilmiştir. MEB tarafindan desteklenen bazı projelerin rakamsal bütçe bilgilerine ulaşılamamış fakat proje kapsamında hangi yatırımların yapıldığı bilgisinden bütçeleri hakkında genel bir fikir sahibi olunabilmiştir. Bazı projelerin toplam bütçeleri hakkında net bir bilgiye ulaşılamadığından bu projelerin bütçe alanına soru işareti (?) simgesi konulmuştur. Ayrica Skoool.tr ve Think.com siteleri ücretsiz olarak MEB'in kullanımına sunulduğundan bu projelerin bütçe bilgisine "Ücretsiz" ifadesi yazılmıştır.

Tablo 5. Okullarda BT altyapısının oluşturulmasına yönelik yapılan projelerin bütçeleri (Budget of the projects for the development of IT infrastructure in schools)

\begin{tabular}{|c|c|c|}
\hline No & Proje Ad 1 & Proje Bütçesi \\
\hline 1 & Endüstriyel Okullar Projesi & 72,7 Milyon \$ \\
\hline 2 & Milli Eğitimi Geliştirme Projesi & 177,2 Milyon \$ \\
\hline 3 & Temel Eğitim Projesi I. Fazı & 300 Milyon \$ \\
\hline 4 & İLSİS Projesi & $?$ \\
\hline 5 & Temel Eğitim Projesi II. Fazı & 300 Milyon \$ \\
\hline 6 & MEB İnternete Erişim Projesi & ? \\
\hline 7 & Mesleki ve Teknik Eğitimin Modernizasyonu Projesi & 18,5 Milyon $€$ \\
\hline 8 & Bilgisayarlı Eğitime Destek Kampanyası & $?$ \\
\hline 9 & Ortaöğretimi Geliştirme Projesi & 80 Milyon $€$ \\
\hline 10 & $\begin{array}{l}\text { Endüstriyel Teknik Öğretim Okulları Bünyesinde Video Konferans Sistemi } \\
\text { (Akıllı Sınıf) Kurulması Projesi }\end{array}$ & $448.869,64 \$$ \\
\hline 11 & MEB Kapasitesinin Güçlendirilmesi Projesi & 4,7 Milyon $€$ \\
\hline 12 & MEBBİS & $?$ \\
\hline 13 & iTEC “Katılımcı Sınıf İçin Yenilikçi Teknolojiler” Projesi & ? \\
\hline 14 & Fırsatları Artırma, Teknolojiyi İyileştirme Hareketi (FATİH) Projesi & 4 Milyon TL \\
\hline
\end{tabular}


Tablo 6. Okullarda BT kullanımının yaygınlaştırılmasına yönelik yapılan projelerin bütçeleri

\begin{tabular}{|c|c|c|}
\hline No & Proje ad 1 & Proje tutar1 \\
\hline 15 & World Links Projesi & $?$ \\
\hline 16 & $\begin{array}{l}\text { Türk-Japon Teknik İş Birliği Kapsamında Anadolu Teknik Liselerinde Endüstriyel } \\
\text { Otomasyon Teknolojileri Bölümü Kurulması Projesi }\end{array}$ & 5 Milyon $\$$ \\
\hline 17 & Eğitim Çerçevesi Projesi I. Fazı & 50 Milyon $€$ \\
\hline 18 & Temel Eğitime Destek Projesi & 145 Milyon \$ \\
\hline 19 & Intel Gelecek İçin Eğitim & $?$ \\
\hline 20 & Internet Radyo TV & $?$ \\
\hline 21 & Microsoft Eğitimde İşbirliği & $?$ \\
\hline 22 & Bilişim Teknolojileri Projesi & $15.221 .000 \$$ \\
\hline 23 & Skoool.tr Portalı & Ücretsiz \\
\hline 24 & Eğitim Çerçevesi Projesi II. Fazı & 50 Milyon $€$ \\
\hline 25 & $\begin{array}{l}\text { Uzaktan Eğitim Sistemi Uygulamalarının AB Ülkelerindeki Uygulama Yöntemleri } \\
\text { Projesi }\end{array}$ & $13.320 €$ \\
\hline 26 & Mesleki Teknik Eğitimde Uygulanabilir Bilgi Sistemi Projesi (METUBIS) & $500.000 \mathrm{TL}$ \\
\hline 27 & Think.Com Portalı & Ücretsiz \\
\hline 28 & Intel Öğretmen Programı & $?$ \\
\hline 29 & Uzmanlaşmış Meslek Edindirme Merkezleri Projesi (UMEM) & $119.270 .553 \mathrm{TL}$ \\
\hline 30 & Hayat Boyu Öğrenmenin Geliştirilmesi Projesi & 15 Milyon $€$ \\
\hline 31 & Türkiye' de Mesleki ve Teknik Eğitimin Kalitesinin Geliştirilmesi Projesi & 33 Milyon $€$ \\
\hline 32 & Hayat Boyu Öğrenmenin Geliştirilmesi Operasyonu 2 & 15 Milyon $€$ \\
\hline
\end{tabular}

\subsection{Projelerin Amaçlarl (Aims of the Projects)}

1984-2013 yılları arasında teknolojinin Türk eğitim sisteminde daha etkin kullanımı için yapılan projelerin amaçları Tablo 7'de belirtilmiştir. Proje amaçları analiz edildiğinde, öncelikle teknoloji aracılığıyla bireylerin eğitimlerine katkıda bulunulmasının amaçlandığı görülmüştür. Projeler sayesinde bir yandan derslikler teknolojik ekipmanla donatılırken diğer yandan öğretmen ve öğrencilere teknolojiyi kullanabilmeleri konusunda eğitimler düzenlenmiştir. Projelerde iç kaynakların ve iş birliği yapılan kurum ve kuruluşlardan elde edilen maddi desteklerin; okulları yenilemek, derslikleri güncel teknolojik ekipmanla donatmak, maddi yetersizlik nedeniyle teknoloji ile tanışamayan öğrencilere eğitimde firsat eşitliğini sunmak, personel ve öğrencilerin okullardan internete erişebilmelerini sağlamak, öğretmenlere yurt içi ve yurt dışında kendilerini alanlarında geliştirebilecekleri fursatlar sunmak gibi amaçlarla kullanıldı̆̆ belirtilmiştir.

Tablo 7. Projelerin amaçları

(Aims of the projects)

\begin{tabular}{|c|c|c|}
\hline \multicolumn{2}{|c|}{ Proje No } & Proje Amaç Özeti \\
\hline \multirow{9}{*}{ 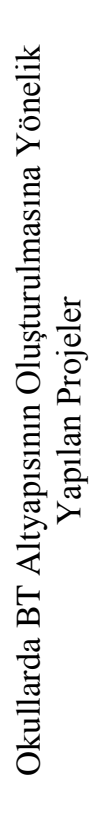 } & 1 & $\begin{array}{l}\text { Proje okullarının donatımını sağlamak, eğitilmiş endüstriyel insan gücünün kapasitesini ve sayısını } \\
\text { artırmak, }\end{array}$ \\
\hline & 2 & Türk eğitim programlarını iyileştirmek ve Türk gençliğini 21. yüzyıla hazırlamak, \\
\hline & 3 & $\begin{array}{l}8 \text { yıllık kesintisiz zorunlu ilköğretimi yaygınlaştırarak evrensel bir kapsama ulaştırmak, ilköğretimin } \\
\text { kalitesini arttırmak, ilköğretim okullarına ilgiyi çoğaltmak, okullarımızı toplum için birer öğrenme } \\
\text { merkezi haline getirmek, }\end{array}$ \\
\hline & 4 & $\begin{array}{l}\text { İl ve İlçe Milli Eğitim Müdürlüklerinin işlevlerinin BT desteğiyle yürütülmesi amacıyla bir yönetim } \\
\text { bilgi sistemi oluşturmak, }\end{array}$ \\
\hline & 5 & $\begin{array}{l}\text { olitikasını desteklemek üzere, eğitim kalitesini yükseltmek, kapasitesini yaygınlaştırmak } \\
\text { mi arttırmak, }\end{array}$ \\
\hline & 6 & $\begin{array}{l}\text { İnternet imkânını her okula uygun bant genişliğinde (ADSL) sağlamak suretiyle e-öğrenme yöntemini } \\
\text { teşvik ederek ögrencilerin bilgiye erişme, bilgiyi kullanma, bilgi üretme ve bilgi paylaşma becerilerini } \\
\text { geliştirmek, }\end{array}$ \\
\hline & 7 & Meslek derslerinin Avrupa Birliği'ndeki gelişmelere uyumunu desteklemek ve niteliğini yükseltmek, \\
\hline & 8 & $\begin{array}{l}\text { Maddi imkânsızlıklar nedeniyle evine bilgisayar alamayan öğrencilerin, bilişim teknolojileri ile okul } \\
\text { sıralarında tanışmalarını sağlamak, }\end{array}$ \\
\hline & 9 & $\begin{array}{l}\text { Değişen ve gelişen küresel yaklaşımlara uygun olarak, orta öğretimde ortak bir genel kültür verilmesi, } \\
\text { esnek ve modüler program çeşitliliğine sahip, öğrencilere ilgi ve yetenekleri doğrultusunda etkin } \\
\text { rehberlik ve danışmanlık hizmetlerinin sunulması, kurumsal ve teknolojik altyapısı güçlü ve daha çok } \\
\text { talep edilebilen nitelikli orta öğretim yapısına ulaşmak, }\end{array}$ \\
\hline
\end{tabular}


Endüstriyel teknik öğretim okul ve kurumlarında görev yapan yöneticilerin, yönetimdeki bilgi ve

10 becerilerini çağdaş yönetim anlayışı içerisinde geliştirmek, bina, tesis, zaman, para, her türlü donatım, üretim, eğitim aracı vb. kaynakların etkili ve verimli bir șekilde kullanımını gerçekleștirmek,

Öğretmenlerin, derslerine ait öğretim programlarını 21. Yüzyıl becerileri ile birleştirip öğrenmenin

11 kalıcı olmasını sağlayarak, çevresinden ve toplumundan sorumlu, kişisel öz-yönelimini sağlamış bireyler yetiştirebilmelerini sağlamak,

Eğitimde teknoloji kullanımını sistemli ve planlı bir politika olarak yaygınlaştırmak, eğitim

12 hizmetlerinin kalitesini yükseltmek, başta öğretmenler ve öğrenciler olmak üzere tüm bireylerin eğitim ihtiyaçlarına cevap verebilecek bir eğitim portalının kurulmasını sağlamak,

13 Hâlihazırda kullanılmakta olan ve alternatif öğretim yöntemlerinin sınıflarda kullanılabilirliğini araştırmak,

14 e-Dönüşüm Türkiye kapsamında 2013 yılı sonuna kadar dersliklere BT araçları koyularak BT destekli öğretim yapılmasını sağlamak,

15 BT'nin eğitimde kullanımını yaygınlaştırmak,

16 Endüstriyel otomasyon teknolojileri bölümlerinin kurularak uluslararası standartlarda donatmak, bu alanlarda eğitim verecek teknik öğretmenleri yurt dışında eğitmek ve öğretim programlarını geliştirmek,

17 Çocukları geleceğe hazırlamak ve teknoloji ile buluşturmak,

18 Türkiye'de yoksulluktan en fazla etkilenen kırsal alanlar ile kentlerin gecekondu bölgelerinde temel eğitimin dışında kalmış kız çocukları, yetişkinler ile risk altındaki çocukları eğitime kazandırmak,

Eğitimde kaliteyi artırmak, bilișim teknolojilerini öğrencilerin hizmetine sunmak, öğretmenlerin bu

19 teknolojileri sınıflarına entegre etmelerine yardımcı olmak ve sınıflarda işlenen derslerde öğrencilerin BT'den bir araç olarak yararlanmalarını sağlamak,

20 İnternet TV aracılığıyla örgün ve yaygın eğitimdeki öğrencilere, öğretmen ve velilere hazırlanan ders destek materyalini sunmak,

21 Bilgisayar okur-yazarı olan öğretmenlerin bilgisayar okur-yazarlık seviyelerini artırmak, olmayanlara bilgisayar okur-yazarlığı kazandırmak,

22 Ülkenin bilişim alanındaki iş gücü açığı ve sektör gereksinimlerine uygun eğitim vermek,

23 Fen ve matematik öğrenmek isteyenlere yenilikçi, etkileşimli ve heyecan verici öğrenme metotlarını en ileri teknolojileri ve cihazları sunmak,

24 Çocukları geleceğe hazırlamak ve teknoloji ile bulușturmak,

25 Avrupa Birliği ülkelerinde uygulanan BT ile eğitimin nasıl verildiği, öğrencilerin bu konulardan nasıl faydalandığını incelemek,

Türkiye'de kadın istihdamı için, ekonomik sektör/mesleklerin ihtiyaçları ve gelişme eğilimleri dikkate

26 alınarak, MEB Kız Teknik Öğretim Genel Müdürlüğü kurumlarının eğitim programları ile sektör/mesleklerin uyumunu sağlayacak sistemi kurmak,

27 Öğretmenleri ve öğrencileri teknoloji yardımıyla yaratıcılığa özendirerek performanslarını yükseltmek, Öğretim sürecinde çoklu değerlendirme yöntemlerinin uygulanmasına imkân tanımak, problem çözme,

28 eleştirel düşünme, işbirliği gibi 21'inci yüzyıl becerilerini kazandırmak, proje bazlı öğrenme yaklaşımını uygulamak,

29 Genç nüfusumuzun niteliğini geliştirerek istihdamını artırmak, Hayat boyu öğrenme stratejilerine uygun, farklı yaş grubu ve eğitim seviyesindeki insanlara, özellikle

30 kadınlara yönelik gelişen teknolojiye ve iş gücü piyasasının taleplerine uygun nitelikli eğitime erişimi artırmak ve $\mathrm{AB}$ standartlarına göre sertifikalandırılacak kurumsal bir çatı oluşturmak,

Genç işsizliğini gidermek, iş dünyasının gereksinimlerine uygun, nitelikli, bilgisi güncel bir işgücü

31 potansiyeli oluşturmak, tüm toplumsal kesimlerin kazançlı çıkacağı, ulusal kalite güvencesine sahip bir mesleki ve teknik eğitim sistemine ulaşmak,

32 Türkiye'de hayat boyu öğrenmenin geliştirilmesi yoluyla insan kaynaklarının gelişimine yardımcı 32 olmak.

\subsection{Projelerin Faaliyetleri (Activities of the Projects)}

1984-2013 yılları arasında teknolojinin Türk eğitim sisteminde daha etkin kullanımı için yapılan projeler sonucunda yapılan faaliyetler Tablo 8'de sıralanmışıtır. Bu proje faaliyetleriyle geniş bir öğretmen ve öğrenci kitlesine ulaşılmaya çalışıldığı görülmektedir. 
Tablo 8. Projelerin faaliyetleri

(Activities of the projects)

74 Endüstri Meslek Lisesi 15 Meslek alanında ekipmanla donatılmış, 200 Endüstri Meslek Lisesi

1 Bilgisayar laboratuvarı ile donatılmış, değişik meslek alanları ile ilgili 42 teknik ders kitabının tercümesi, basım ve dağıtımı gerçekleştirilmiş, 13 Meslek alanında Eğitim Programları yenilenmiştir

23 İlde 147 İlköğretim, 37 Genel Lise, 16 Anadolu lisesi, ve 8 Anadolu Öğretmen Lisesi olmak üzere

2208 Müfredat Laboratuvar Okulu (MLO) Eğitim Materyalleri ile donatılmış, 235 Bilgisayar Deneme Okuluna birer bilgisayar laboratuvarı ve öğretmen odalarına birer bilgisayar kurulmuştur.

2.802 ilköğretim okuluna 3.188 bilgi teknolojisi sınıfı kurulmuştur. 22.854 kırsal kesim okulu için 45.000 bilgisayar, donanım, yazılım ve çevre ekipmanları satın alınmıştır. Donanım alınan firmalar

36.665 öğretmene, yazılım alınan firmalar 9.251 öğretmene eğitim vermiştir. 221.000 öğretmen, bilgisayar sınıflarının, donanımı ve yazılımının etkin bir şekilde kullanabilmek amacıyla eğitim almışlardır. İlköğretim müfettişlerine ve formatörlere 1500 dizüstü bilgisayar ve MEB müfettişlerine 130 dizüstü bilgisayar, 1 anabilgisayar alınmıştır.

41925 bilgisayar, 648 yazıc1, 81 sunucu bilgisayar, 81 kesintisiz güç kaynağı ve tüm iller için ağ cihazları alınmıştır.

3000 ilköğretim okulunun 4002 sınıfina bilgisayar laboratuvarları kurulmuş, kırsal ve gecekondu bölgelerindeki 4000 ilköğretim okuluna eğitim materyalleri alınmıştır. 1340 özel eğitime ihtiyaç

5 duyan zihinsel engelliler sınıfına öğrenmeyi kolaylaştırıcı ekipmanlar, görme engelli öğrenciler için 1035 braille daktilo, 48 işitme engelliler ilköğretim okuluna 75 işitme cihazı seti, işitme ve görme engelli öğrenciler için 70 bilgisayar laboratuvarı kurulmuştur.

Protokol gereği 31 Aralık 2003 tarihi itibariyle 1.748, 31 Aralık 2004 tarihi itibariyle 12.241, 31 Aralık 2005 tarihi itibariyle 8.158, 31 Aralık 2006 tarihi itibariyle 5.848, 17 Ekim 2007 tarihi

6 itibariyle 1.037 olmak üzere toplam 29.027 okul/kuruma geniş bant ADSL bağlantısı ile Internet bağlanmıştır. 2008 yılında İlköğretim öğrencilerinin \%93'üne, ortaöğretim öğrencilerinin ise

\%99'una internet erişimi sunulmuştur.

Beş Ilde Bölge Koordinatörlukleri Kurulmuştur. Ulusal Standart ve Program Geliştirme Grubu

7 (USPGG) kurulmuş, mevcut meslekî ve teknik eğitim programları önceliklendirilmiş, yeterlilikler belirlenerek teknik çalışma grupları kurulmuş, grup yönlendiricileri ve grup üyeleri eğitilmiş, meslek dersleri öğretmenlerinin yeterlilikleri belirlenmiştir.

8 MEB ve Türkiye Bilişim Sanayicileri ve İşadamları Derneği 300 bin bilgisayar bağışı toplama projesi başlatmiştır.

91629 ortaögretim kurumuna dizüstü bilgisayar, projeksiyon cihazı ve fotokopi makinesinden oluşan temel BT ekipmanları alınmıştır.

Ankara İskitler Anadolu Teknik Lisesi, Antalya Merkez Anadolu Teknik Lisesi, Gaziantep Mehmet Rüştü Uzel Anadolu Teknik Lisesi, İstanbul Pendik Anadolu Teknik Lisesi, İzmir Mazhar Zorlu

10 Anadolu Teknik Lisesi, Trabzon Merkez 80.Y1l Anadolu Teknik Lisesi ve Van Merkez Anadolu Teknik Lisesinde olmak üzere toplam 7 coğrafi bölgemizden 7 Anadolu Teknik Lisesi bünyesinde Video Konferans Sistemi (Akıllı Sınıf) kurularak 13.02.2007 tarihinde açılışı yapılmıştır.

11 Ülke genelinde ilköğretim okullarında görev yapan müdürlere eğitimler verilmesi planlanmıştır. Projenin tamamı MEB insan kaynakları ve yerel mali kaynaklar ile gerçekleştirilmektedir. Projede şu modüller yer almaktadır; Bilgiye Erişim Portalı, Skoool.tr, Global Gateway Think.com, İLSİS, Açık Öğretim Lisesi ve Mesleki Açık Öğretim Lisesi Programı, Açık İlköğretim Okulu Programı, Özlük Modülü, Kişisel Bilgiler Modülü, MEB Sorgu Modülü, İnceleme-Soruşturma Modülü, Teftiş Modülü, Eksik Personel Modülü, Atama Modülü, Başvuru İşlemleri Modülü, Başvuru Onay Modülü, Norm İşlemleri Modülü, Kontenjan Modülü, Resmi İşlemleri Modülü, Özel Öğretim Kurumları Modülü, Rehberlik ve Araştırma Merkezleri Modülü, Taşınır Mal Yönetmeliği Modülü,

12 e-Burs Modülü, e-Yurt Modülü, Bilgisayarlı Eğitime Destek Modülü, Kadrosuz Usta Öğretici Modülü, İlköğretim Müfettiş ve Yardımcıları Yolluk Modülü, Kitap Seçim Modülü, Yan Ödeme ve Özel Hizmet Tazminatı Modülü, Evrak Modülü, Bütçe Modülü, DİSİS Modülü, Yurt dışı Modülü, YOSİS Modülü, İMD Modülü, MEİS Sorgu Modülü, Hizmet İçi Eğitim Modülü, Performans Değerlendirme Modülü, Beden Eğitimi, Spor ve İzcilik Modülü, EARGED Araştırma Takip Modülü, Sekreterya ve Talep Takip Uygulamaları, e-Mezun Portalı, Bu Benim Eserim, Okul Vaka Analiz Raporu, Kurumsal Kapasite Envanteri, METSİS Modülü, Engelli Öğrenci Modülü, Maaş Modülü.

13 Farklı branşlardan öğretmenlerin sınıflarında uygulayabilecekleri Proje Tabanlı Öğrenme Modeli üzerine kurulu Öğrenme Hikâyeleri güncel web araçları ile uygulamaya konulmuştur. 
öğretmen ve öğrencilere e-kitap (tablet bilgisayar) verilmesi planlanmaktadır.

15

Öğretmenlere Dünya Bankası ve MEB Eğitim Teknolojileri Genel Müdürlüğü işbirliğiyle üç faz eğitimi verilmiştir.

İki okulda toplam 17 atölye ve laboratuvar modern ve yüksek teknoloji ürünü araç-gereçle komple donatılmıştır. 25 öğretmenimizin 3-9 ay süre ile Japonya'da Endüstriyel Otomasyon Teknolojileri alanında eğitilmeleri gerçekleştirilmiştir. 6 Japon uzman 5 yıllık proje süresince Ülkemizde görevlendirilmişlerdir.

171610 BT sınıfı kurulmuş, ayrıca 28.315 Okulun BT sınıfları için web tabanlı yazarlık yazılımı satın alınmış, 924 ilçe merkezine teslim edilmiştir.

Öğretmen, yönetici, velilerden oluşan yaklaşık 100.000 kişiye eğitim verilmiștir. 81 okul, 775

18 derslik,11 Halk Eğitim Merkezi,37 Lojman, 20 Yurt, 1 Spor Salonu, 3 Yemekhane inşa edilmiştir.

过 18 Yeni programlara uygun olarak öğretmen kitabı, öğrenci kitabı ve çalışma kitabı üçlü set halinde tüm dersler için hazırlanmış ve basımına katkı vermek için 1 milyon Avroluk kâğıt satın alınmıştır.

MEB'e bağlı resmi okullarda görev yapan 97.292 öğretmen söz konusu program kapsamında eğitilmiştir.

20 Örgün ve yaygın eğitimdeki öğrencilere, öğretmen ve velilere MEB tarafından hazırlanan ders destek materyalini sunmak amacıyla Internet TV yayın hayatına başlamıştır.

21 Uzaktan eğitim yöntemiyle bir öğretmen eğitimi programı başlatılmıştır.

2220 Anadolu teknik lisesi bünyesinde bilişim teknolojileri bölümü açılmıştır.

Intel Firması tarafindan orijinal portalın matematik, fizik, kimya ve biyoloji alanlarında \%25'lik k1smı

23 Türkçeleştirilmiş ve Bakanlık web sayfasından link verilmek suretiyle http://skoool.meb.gov.tr adresinden yayınına başlanmıştır.

24 BT sınıfı bulunan 2000'in üstünde okulun bilgisayarlarının yenilenmesi ve 2500'den fazla ilköğretim okulunda 15+1 BT sınıfi kurulması planlanmıștır.

25 Erkek Teknik Öğretim Genel Müdürlüğünde çalışan 7 personel tarafindan AB ülkelerindeki uzaktan eğitim uygulamaları incelenmiştir.

2010 yılı ocak ayında örneklem olarak seçilen 15 ilde kadın istihdamı ağırlıklı seçilmiş sektörlerde

26 faaliyet gösteren SSK ve TOBB'a kayıtlı 10-49 istihdamlı işyerlerinde bazı kişilere anket uygulanmıştır. Bu anketlerin sonuçlarına dair herhangi bir veriye ulaşılamamıştır.

MEB ile Oracle Eğitim Vakfı arasında 01.03.2007 tarihinde Think.com Eğitim Portalı iş Birliği

27 Protokolü imzalanmıştır. Bu protokol çerçevesinde Think.com Eğitim Portalı 2006-2007 yılında 6 ilden seçilen 20 okulumuzda uygulanmış olumlu sonuçlar alınmıştır. İçinde bulunduğumuz 20072008 eğitim ve öğretim yılında genişletilerek 28 ilimizde uygulanmıştır.

28 Ağustos 2011 yılı itibariyle MEB'e bağlı resmi okullarda görev yapan 179.969 öğretmen söz konusu program kapsamında eğitilmiştir.

2981 ilde faaliyet gösteren 121 teknik ve endüstri meslek lisesinin teknolojik donanımı (makineteçhizat) iş piyasasının ihtiyaçları doğrultusunda yenilenmiştir.

Hayat boyu öğrenme politikalarının oluşturulması, Avrupa yeterlikleri doğrultusunda kredi transfer sisteminin oluşturulması, hayat boyu öğrenme koordinasyon merkezlerinin oluşturulması, hayat boyu

30 öğrenme öğretmen eğitimi, Hayat boyu öğrenme konusunda farkındalık oluşturulması, hayat boyu öğrenme hibe programının başlatılması, hayat boyu öğrenme koordinasyon merkezlerine ekipman desteğinin sağlanması faaliyetleri gerçekleştirilmiştir.

21 pilot ilde uygulama başlatılmıştır. Pilot iller: Ağrı, Bingöl, Bitlis, Çorum, Diyarbakır, Erzincan,

31 Gaziantep, Hakkâri, Iğdır, Kahramanmaraş, Kastamonu, Kilis, Mardin, Muş, Ordu, Rize, Sivas, Siirt, Trabzon, Van ve Yozgat.

323000 okulda 4002 BT sınıfının kurulum çalışmaları devam etmektedir.

\section{SONUÇ ve TARTIŞMA (RESULT AND DISCUSSION)}

Türk Eğitim Sisteminde teknolojinin daha etkin kullanımı için 1984-2013 yılları arasında birçok proje yapılmıştır (Tablo 2). Fakat bu projeler hakkında veri toplanmaya çalışıldığında, projeleri yürüten kişi, kurum ve kuruluşlar tarafından proje bilgilerinin düzenli olarak tutulmadığ 1 anlaşılmıștır. Bu durumdan; otuz yıldır eğitim sistemine milyonlarca dolarlık teknolojik yatırım yapıldığı fakat bu yatırımların yeterli düzeyde analiz edilmediği sonucuna ulaşılmıştır. Yapılan yatırımların amaçlanan noktaya ulaşmaya katkı sağlayıp sağlamadığına bakılması ve gelecekte yapılacak yatırımların bu doğrultuda planlanabilmesi için bir proje veri tabanı oluşturulması ve bu projelerin detaylı olarak analiz edilmesi gerektiği düşünülmektedir.

1984-2013 yılları arasında Milli Eğitim Bakanlığı'nın okullarda BT altyapısının oluşturulması ve eğitimde BT kullanımının yaygınlaştırılmasına yönelik yürüttüğü ya da desteklediği projeler Tablo 2'de verilmiştir. Bu tabloya bakıldığında, MEB'in okullarda BT altyapısı oluşturulmasına yönelik projelerden çok BT kullanımının yaygınlaştırılmasına yönelik projeler gerçekleştirdiği görülmektedir. Altyapı projeleri 1984 yılında başlamış olup 1986-1989 ve 1998 yılları arası hariç günümüze 
kadar sürekli bu konuda devam eden projeler yapılmıştır (Tablo 4). BT kullanımına yönelik projelerin başlangıç tarihi 1998 yılı olmasına rağmen sayıca altyapı projelerinden oldukça fazladır. Günümüzde 3 adet BT altyapısı oluşturmaya yönelik, 6 adet de BT kullanımının yaygınlaştırılmasına yönelik proje faaliyetlerine devam etmektedir (Tablo 4).

1984-2013 yılları arasında yapılan, okullarda BT altyapısı oluşturmaya yönelik projelerin bütçeleri (Tablo 5) ile BT kullanımına yönelik projelerin bütçeleri (Tablo 6) karşılaştırıldığında, toplam bütçelerin birbirine yakın olduğu görülmüştür. Tablo 4 incelendiğinde öncelikle altyap1 oluşturulan projelerin yapıldı̆̆ 1 , sonrasında teknolojinin kullanımının öğretilmesine yönelik projelerin hızlıca başladığı görülmektedir. $\mathrm{Bu}$ sıralamaya "önce bilgisayar sahibi yapmak mı yoksa bilgisayar kullanmayı öğretmek mi gerekir?" sorusu çerçevesinde bakılarak atılan adımın mantıklı olduğu düşünülmektedir.

Projeler incelendiğinde, teknolojinin eğitim sistemine entegre edilmesine yönelik okullarda yapılan projelerin çoğunlukla Milli Eğitim Bakanlığı tarafından yapıldığ görülmüştür. Bazı projeleri ise Dünya Bankası fonları, Avrupa Yatırım Bankası fonları, TİKA (Türk İşbirliği ve Koordinasyon Ajansı Başkanlığı), JICA (Japan International Cooperation Agency) fonları ve $\mathrm{AB}$ fonları ile finanse edilmiştir (Şekil 1). Teknolojinin eğitim sisteminde daha etkin kullanımı için yapılan projelere MEB'den sonra en çok Dünya Bankası tarafindan maddi destek verilmiştir [5].

1984-2013 yılları arasında eğitim sistemine milyonlarca dolarlık yatırım yapıldığı görülmektedir. Bununla birlikte kurumsallaşamamaktan dolayı önceki yıllarda yapılan projelerin sonuçlarının analiz edilmediği, projeleri destekleyen kurum ve kuruluşların bile destekledikleri projelere ait veri tabanı oluşturmadıkları, Milli Eğitim Bakanlığı'nın da yapılan projelere ait verileri yeterince tutmadığı ortaya çıkmıştır. Yapılacak milyarlarca dolarlık projelerin önce öğrenciler üzerindeki etkisi analiz edilirse ancak o zaman etkili olabileceği düşünülmektedir. Örneğin FATİH projesiyle 2011 yilından bugüne öğrencilere eğitim amaçlı kullanması için tablet bilgisayarlar dağıtılmaktadır. Fakat dağıtılan bu tablet bilgisayarların öğrenciler tarafından gerçekte nasıl kullanıldığına bakılmaksızın halen dağıtımı devam etmektedir. Ayrıca ilk dağıtılan tablet bilgisayarlar bugünün teknolojisine yenik düşmüş durumda olduğundan eğitime harcandığı sanılan milyonlarca dolar aslında boşa harcanmaktadır. Elbette bu analiz için en önemli adım bir veri tabanı oluşturulması ve yapılan projelerin ortaya çıkardığı etkilerin ilerleyen süreçte bu veri tabanına kayıt edilmesidir. Veri tabanının gerekliliği, bu çalışmanın veri toplama aşamasında ulaşılan kaynakların birçoğuna bugün ulaşılamıyor olmasından da anlaş1labilmektedir.

\section{5. ÖNERILLER (SUGGESTIONS)}

Araştırma sonucunda elde edilen bulgular doğrultusunda;

1. Milli Eğitim Bakanlığ 1 tarafından, bugüne kadar yapılan projelerle ilgili veri tabanı oluşturulmasının faydalı olacağı düşünülmektedir.

2. Yapılan projelerin eğitim sistemine etkilerinin analiz edilebilmesi amacıyla Milli Eğitim Bakanlığı bünyesinde oluşturulacak bir birim tarafından; BT alanında yapılan tüm projelerin etkilerinin araştırılmasının gerektiği düşünülmektedir.

3. Yeni yapılacak projelerin amaca uygunluğunun araştırılması için de üniversitelerle işbirliğine gidilmesinin yolları aranmalıdır.

4. Teknolojinin çok hızlı eskidiği göz önünde bulundurulacak olursa, donanımsal yatırım projeleri yerine ağırlıklı olarak içerik oluşturma ve diğer eğitsel yatırım projelerinin desteklenmesi gerektiği ve bu durumun kaynakların etkili ve verimli kullanılması açısından daha faydalı olacağı düşünülmektedir.

5. Her yeni çıkan teknolojinin eğitim sisteminde kullanılmasının uygun olmayabileceği, eğitim sisteminde kullanılmadan önce bu teknolojilerin doğuracağı sonuçları öngörebilecek BT uzmanlarından görüş alınması gerektiği düşünülmektedir.

\section{KAYNAKLAR (REFERENCES)}

[1] Y. Göktaş, Z. Yıldırım, S. Yıldırım, "Bilgi ve İletișim Teknolojilerinin Eğitim Fakültelerindeki Durumu: Dekanların Görüşleri”, Eğitim ve Bilim, 33(149), 30-50, 2008. (Archived by WebCite $^{\circledR}$ at http://www.webcitation.org/6MNrBA4JG)

[2] Milli Eğitim Bakanlığı Projeler Koordinasyon Merkezi Başkanlığı, BT Entegrasyonu Temel Araștırması Raporu, Temel Eğitim Projesi II. Fazı, Bilgitek Eğitim Danışmanlık ve Taahhüt A.Ş, Ankara, Türkiye, 2007. (Archived by $\quad$ WebCite $^{\circledR}$ at http://www.webcitation.org/6MNrrIFIN)

[3] E. O. Patrikas, R. A. Newton, "Computer Literacy among Entering Allied Health Students and Faculty: A Process for Rational Technology Planning", T.H.E. Journal (Technological Horizons In Education), 27(5), 60-65, 1999. (Archived by WebCite ${ }^{\circledR}$ at http://www.webcitation.org/6MNsP5EVB)

[4] F. Turan, Milli Eğitim Bakanlığı Bilişim Sisteminin Bir Alt Sistemi Olarak E-Okul Uygulamasına İlișkin İlköğretim Okullarındaki Yönetici, Öğretmen, Öğrenci ve Veli Görüşleri, Yüksek Lisans Tezi, Akdeniz Üniversitesi, Sosyal Bilimler Enstitüsü, Türkiye, 2010. (Archived by $\quad$ WebCite $^{\circledR}$ at http://www.webcitation.org/6MNsbVaFS)

[5] Web Tabanlı E-Denetim ve E-Performans - Milli Eğitim Bakanlığı Projeler Koordinasyon Merkezi Başkanlığ 1 , http://wbeeeuproject.org/index.php?option $=$ com content $\&$ view $=$ article $\&$ id $=63$ $\underline{\text { \&Itemid=53\&lang=tr, }}, \quad 04.01 .2014$. (Archived by WebCite $^{\mathbb{R}}$ at http://www.webcitation.org/6MNt7yUm0)

[6] A. Yıldırım, H. Şimşek, Sosyal Bilimlerde Nitel Araştırma Yöntemleri, Seçkin Yayıncılık, Ankara, Türkiye, 2006.

[7] Çıraklık ve Yaygın Eğitim Genel Müdürlüğü Hayat Boyu Öğrenme Yürütme Kurulu Sekretaryası, Türkiye Hayat Boyu Öğrenme Strateji Belgesi ve 2009-2013 Dönemi Hayat Boyu Öğrenme Faaliyet Planı, 
Çıraklık ve Yaygın Eğitim Genel Müdürlüğü, Ankara, 2010. (Archived by WebCite $^{\circledR}$ at http://www.webcitation.org/6MNqdexHf)

[8] Mili Eğitim Bakanlığı Eğitim Teknolojileri Genel Müdürlüğü, Stratejik Plan 2010-2014, Eğitim Teknolojileri Genel Müdürlüğü, Türkiye, 2010. (Archived by WebCite $^{\circledR}$ at http://www.webcitation.org/6MNrNRHDS)

[10] Milli Eğitim Bakanlığı Projeler Koordinasyon Merkezi Başkanlığı, Stratejik Plan (2010-2014), Projeler Koordinasyon Merkezi Başkanlığı, Türkiye, 2010. (Archived by WebCite $^{\mathbb{B}} \stackrel{\text { at }}{\text { a }}$ http://www.webcitation.org/6MNs4ZRBq)

[11] Internet: Milli Eğitim Bakanlığı Strateji Geliştirme Daire Başkanlığı

http://sgb.meb.gov.tr/www/dokumanlar/icerik/30,

Dokümanlar, Archived by WebCite ${ }^{\circledR}$ at http://www.webcitation.org/6WD7cBpf8)

[12] Internet: Bilim Sanayi ve Teknoloji Bakanlığı Strateji Geliştirme Başkanlığı, http://strateji.sanayi.gov.tr/DocumentList.aspx?Ing=tr, 04.01.2014. (Archived by http://www.webcitation.org/6WD8Ke6Q2)
[9] Internet: Mesleki ve Teknik Eğitim Genel Müdürlüğü - Projeler, http://mtegm.meb.gov.tr/www/projeler/kategori/11/2/, 04.01.2014. (Archived by WebCite ${ }^{\circledR}$ at http://www.webcitation.org/6MNrd81rV)

[13] Türkiye İstatistik Kurumu, Türkiye Eğitim Harcamaları Araștırması 2002, Türkiye İstatistik Kurumu, Ankara, Türkiye, 2006. (Archived by WebCite ${ }^{\circledR}$ at http://www.webcitation.org/6MNskqmwz)

[14] Internet: Sektörlere Göre Kamu Yatırımları (Proje Bazında), http://www2.dpt.gov.tr/kamuyat/sektor.html, 04.01.2014. (Archived by WebCite $^{\circledR}$ at http://www.webcitation.org/6MNrSLfkR)

[15] Türkiye'de Hayat Boyu Öğrenmenin Geliştirilmesi Projesi, Uluslararası Hayat Boyu Öğrenme Konferansı Raporu, İstanbul, Türkiye, 2012. (Archived by WebCite $^{\circledR}$ at http://www.webcitation.org/6MNszh2lI)

[16] Internet: Projeler - Çelik, http://salihcelik.net/urunler.php?kat=41, 04.01.2014. (Archived by WebCite $^{\circledR}$ at http://www.webcitation.org/6MNsDhp3p) 